\title{
A lama e suas marcas: neoextrativismo e seus efeitos em um contexto de desastre
}

\section{Raquel Oliveira Santos Teixeira*}

UNIVERSIDADE FEDERAL DE MINAS GERAIS (UFMG), BRASIL

\section{Resumo:}

Esse artigo aborda o desastre da Samarco no Rio Doce, onde uma barragem de rejeitos se rompeu causando 19 mortes. Cerca de 60 milhōes de metros cúbicos de rejeitos minerários foram lançados ao rio. Através da perspectiva da sociologia dos desastres e da etnografia dos encontros entre as vítimas e as instituiçóes dedicadas à gestáo da crise, o artigo discute os procedimentos institucionais e suas consequências para os moradores atingidos. Nesse campo conflitivo, a narrativa corporativa linear de evento, impactos e compensação contrasta com a experiência do desastre da perspectiva daqueles que permanecem diariamente afetados. Enquanto os procedimentos institucionais e corporativos procuram estabilizar e restringir a definição dos danos, os atingidos denunciam a severa transformação de suas vidas a partir da presença permanente da lama que 'não sai'.

\section{RESUMEN:}

Este artículo trata del desastre de Samarco en el Rio Doce, donde una represa de residuos se rompió causando 19 muertes. Aproximadamente 60 millones de metros cúbicos de residuos mineros fueron lanzados al río. Desde la perspectiva de la sociología de los desastres y de la etnografía de los encuentros entre las víctimas y las instituciones enfocadas en la gestión de la crisis, el artículo discute los procedimientos institucionales y sus consecuencias para los habitantes afectados. En este campo conflictivo, la narrativa corporativa lineal de evento, impactos y compensación entra en contraste con la experiencia del desastre desde la perspectiva de aquellos que siguen sufriendo diariamente sus efectos. Mientras los procedimientos institucionales y corporativos buscan estabilizar y restringir la definición de los daños, las víctimas denuncian la dura trasformación de sus vidas a partir de la constante presencia del barro que "no se va".

*raqueloliveira2002@gmail.com / raqueloliveira2002@fafich.ufmg.br 
ito meses após o rompimento da barragem de Fundáo,
nos encontramos com P., morador de Bento Rodrigues,
distrito de Mariana devastado pela onda de rejeitos minerários. Não foi difícil encontrar sua casa, ele a havia indicado como a única naquela rua onde haveria uma bandeira do Movimento dos Atingidos por Barragem (MAB) pendurada na janela. Ele tinha aspecto magro, abatido e sua sala estava tomada por telas, caixas, peças de isopor, pincéis e tintas. P. está a pintar continuamente as imagens, lembranças e paisagens de sua comunidade devastada pela lama. Sobre o sofá estão suas telas: duas retratam a igreja de Nossa Senhora das Mercês, outro a colheita de pimenta e em um deles a figura de sua sobrinha, falecida na tragédia. Ele nos explica seu processo criativo:

Dizem que o quadro a gente tem que começar pelo fundo, vir de dentro para fora, mas estes não são assim. Não fiz assim. Eu não tenho as fotografias, então não vou seguindo as linhas. Eu vou seguindo as imagens que eu tenho aqui [ele leva as mãos à cabeça]. Então, se eu tenho uma imagem eu começo por ela e vou lembrando o resto, vou lembrando a paisagem. Quer dizer, é de fora, a lembrança primeiro, para dentro, para dentro do Bento [Rodrigues].

Ele nos aponta o quadro que está pintando. Em primeiro plano, há a bodega (venda) de J. e P. segue nos explicando:

tá vendo? Ali nesse lado era a casa e o pomar do H., vê as jabuticabas dele? Do lado, a casa de N., ela saía toda tarde na rua vendendo pastel com a caixinha dela... Aqui o bambuzal, a cerca, o curral de H. e a estrada pra Santa Rita lá no fundo, porque era o que a gente via dali... 
P. apresenta suas telas e também sua horta agora confinada a um conjunto de garrafas PET distribuídas sobre um jirau... Em julho de 2016, quando estava realocado na cidade de Mariana, recebia 880,00 reais mensais da Samarco. Durante algumas horas de conversa, ele narrou a tragédia e avaliou como se sentia:

eu sou muito grato ao pessoal de Mariana que se mobilizou e doou as roupas pra gente, mas eu digo que agora parece que a gente tá feito urubu. É. Urubu mesmo, quer dizer pra gente ter, pra gente ganhar, outros tem que perder... Eu olho no armário, essa blusa [ele mostra a blusa que está vestindo], eu sei, é minha, mas... não é a mesma coisa. O mesmo com as coisas da Samarco, ela comprou e pôs aqui os móveis, uma porcaria, uma cama que canta, um armário que já quebrou os pés... No Bento [Rodrigues] eu tinha as minhas coisas, meu armário, minha cama, o armário mesmo foi da minha avó e só que ela morreu tem 14 anos... aqui, também não tenho sossego, se alguém faz um barulho lá embaixo eu tenho que ir à janela ver, eu fico assim... tomo três medicamentos. Um deles nem preciso, só uma vez por semana, quando acordo ruim, assim, tremendo... Ai eu sei que vai ser dificil e tomo...

P. relatou também a perda de sua sobrinha e acentuou:

o psicólogo me perguntou como estou me sentindo, eu disse, - ah, eu me sinto, desgastado. Desgastado porque foram 30 anos construindo nossas coisas no Bento [Rodrigues]. Nós passamos lá trinta anos 
em construção. De primeiro, mãe morava de aluguel lá, depois foi comprou um terreno $e$ nós fizemos uma casa muito boa pra ela e nós irmáos fomos fazendo pra gente também. Era todo mundo junto... eu digo que essa distância que nós estamos vivendo em Mariana é até bom, porque eu não quero mais, não quero mais aquele amor que eu tinha por meus sobrinhos, hoje eu falo que não vou ser mais a mesma coisa com eles, porque eu não quero me apegar mais. Não quero de novo, não quero tudo o que eu sofri...

A este relato acrescento o depoimento de M., moradora da comunidade de Paracatu de Baixo, em abril de 2017, quando já se somavam dezesseis meses de desastre. Se aproximando da igreja pela qual costumava zelar, ela enfatizou:

Ai a gente tá pedindo pra limpar a igreja, de menos por fora. Por fora náo vai limpar não. A comunidade não vai deixar. Quer que limpa por dentro e póe porta, póe banco, mas por fora não é pra mexer.

- Por que?

A comunidade não quer que mexe. Ela vai ficar do jeito que tá ali fora. Vai ficar marcada. 


\section{Igreja de Santo Antônio \\ Paracatu de Baixo}

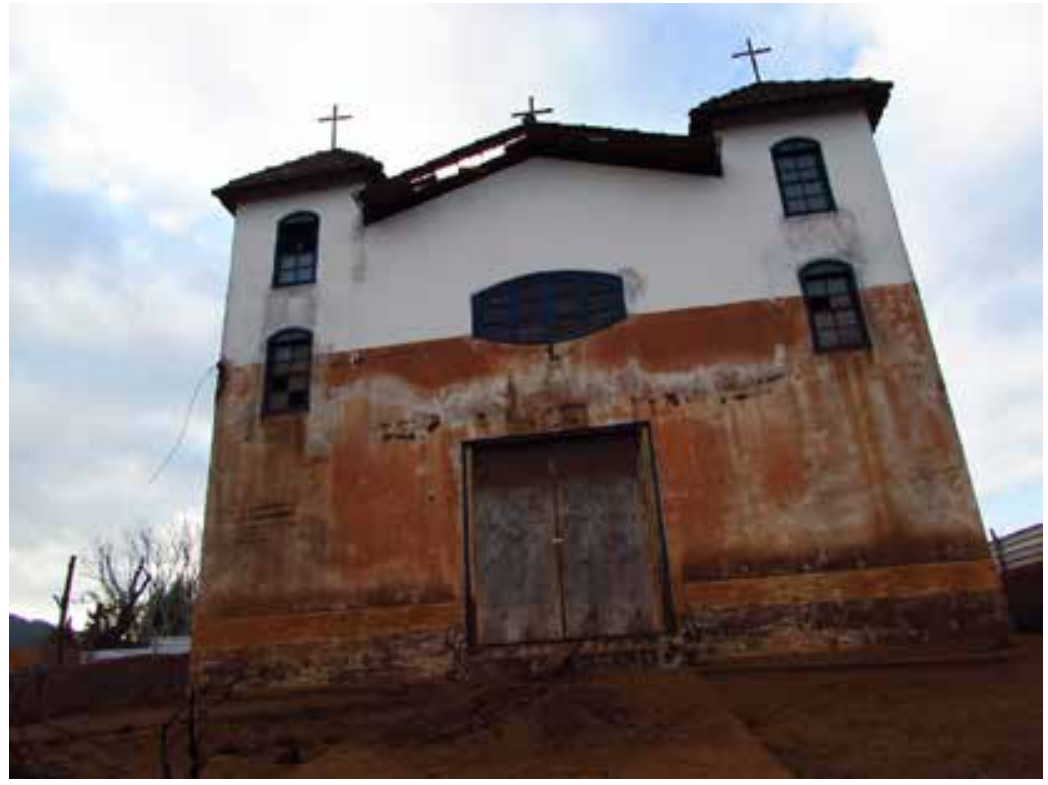

Foto: Marcos Zucarelli, julho de 2016. Arquivo GESTA, 2016.

Marcas de um desastre em curso. No corpo, na memória, na paisagem, nos relacionamentos que tecem e sustentam o engajamento com o território, com as famílias e vizinhos. Os apontamentos de campo e testemunhos citados derivam de nossa trajetória de pesquisa e extensão universitária junto aos grupos sociais afetados pelo desastre da Samarco, sobretudo, as comunidades de Bento Rodrigues e Paracatu de Baixo, no município de Mariana, Minas Gerais, Brasil.

Trata-se do rompimento da barragem de Fundão de propriedade da empresa minerária Samarco, subsidiária das companhias Vale S. A e BHP Billiton Brasil. Com a ruptura da represa no dia 05 de novembro de 2015, foram liberados cerca de 60 milhóes de metros cúbicos de rejeitos minerários carreados ao Rio Doce e deste até a costa brasileira, no estado do Espírito Santo. Os rejeitos percorreram 
mais de 600 quilômetros e atingiram a foz no Oceano Atlântico. Dezenove pessoas morreram imediatamente e centenas de moradias foram destruídas. Danos significativos também foram causados à pesca e à qualidade da água que é fonte de abastecimento para milhares de habitantes das cidades e povoados localizados às margens do rio (Zhouri et al, 2016; Zhouri et al, 2017).

$\mathrm{O}$ objetivo deste artigo consiste, sobretudo, em situar os acontecimentos de Mariana sob a ótica sociológica dos desastres, interpelando seus duradouros efeitos a partir de um complexo processo que engendra formas específicas de subjetivação política. A definição antropológica de desastre o compreende como "fenômeno em processo" (Silva, 2004:204) que resulta de escolhas políticas e condiçóes socioeconômicas e culturais. Nessa perspectiva, os desastres se apresentam como formas de ação social com efeitos disruptivos capazes de dissolver rotinas, estratégias de vida, formas de organização social e sentidos historicamente compartilhados. Como processos físicos e sociais (Oliver-Smith, 2002; Valencio, 2009) os desastres nos revelam importantes facetas do extrativismo. Embora tratados comumente como eventos extraordinários resultantes de fatores geofísicos ou tecnológicos acidentais, os desastres nos apontam não para condiçóes excepcionais, mas para a ordem social das coisas e seus "efeitos de lugar" (Bourdieu, 2012), ou seja, para formas ordinárias, duradouras e perversas de produção social da vulnerabilidade. Conforme destaca Thomas (1993:119)

Una consecuencia importante de esta determinación es que un desastre no debería considerarse en si como un fenómeno "anormal" en lo que se refiere a su contenido o impacto; sino solamente en cuanto a la irregularidad o espaciamiento temporal de su aparición en un territorio determinado. Más bien debe ser visto como la concreción de un particular estado de normalidad, como una expresión de las condiciones normales 


\section{$y$ prevalecientes de una sociedad operando}

bajo circunstancias extremas.

A mobilização da literatura das ciências sociais a respeito dos riscos e desastres revela-se fundamental ao permitir problematizar as leituras estritamente técnicas e quantitativas dos riscos, na medida em que estas desconsideram "que tanto as causas dos danos como a magnitude de suas consequências estão mediadas por experiências e interaçôes sociais" (Guivant, 1998:3). Os desastres, em particular, são "materialmente e socialmente construídos, canalizados e distribuídos de modo variado [...] de acordo com as instituiçôes e práticas políticas, sociais e econômicas" (Oliver-Smith, 2002:24). Nesse sentido, não somente os chamados 'fatores de ameaça' são produzidos ou mediados por forças sociais, mas se tornam efetivos em determinados contextos sociopolíticos.

No cenário em pauta, tais condiçóes apontam para as práticas econômicas e as relaçóes sociopolíticas que operam nas "circunstâncias extremas" (Thomas, 1993:119) do neoextrativismo (Gudynas, 2015). Autores como Hogenboom (2012) caracterizam este momento pelas políticas minerárias "pós-neoliberais", adjetivo que designaria os regimes emergentes de esquerda na América Latina, os quais atribuem ao Estado um importante papel em termos da redistribuição de renda e seu protagonismo na inserção das economias locais no mercado global. Tais medidas se concretizam em uma espécie de 'Estado compensador' que utiliza a receita pública proveniente dos novos extrativismos em seus programas de redistribuição de renda ou de investimentos sociais (Milanez \& Santos, 2013). O prefixo neo opera entáo como marcador para assinalar que a revisão de alguns aspectos da política neoliberal não significou, nesse campo, uma mudança substantiva, de modo que, não se trata de uma "completa inovação institucional, mas sim uma combinação de aspectos historicamente enraizados na paisagem econômica e política latino-americana" (Milanez \& Santos, 2013:123).

No caso brasileiro, os dados oficiais divulgados pelo Instituto 
Brasileiro de Mineração (IBRAM) apontam que a produção mineral do país saltou de cinco bilhóes de toneladas em 2001 para cinquenta e dois bilhóes de toneladas em 2011. Com efeito, multiplicaram-se as intervençóes previstas nos territórios, incluindo o planejamento, funcionamento e/ou licenciamento de nove minerodutos em Minas Gerais. Nesse contexto, os movimentos ascensão e retração dos preços e as formas de resposta das corporaçôes a tais oscilaçóes contribuem para a proliferação das ameaças, já que a intensificação da produção é acompanhada por correspondentes esforços de aceleração e flexibilização dos processos de licenciamento ambiental (Zhouri, 2017).

Com efeito, riscos e desastres são forjados na confluência de fatores estruturais, organizacionais e operacionais (Porto, 2000) relativos à conjuntura de expansão das fronteiras minerárias, com a consequente vulnerabilização dos segmentos sociais afetados. Por fatores estruturais entendemos o conjunto das dinâmicas econômicas e sociais que apontam para um modelo de desenvolvimento extrativo que leva à contínua e sistemática exposição aos perigos múltiplos decorrentes das atividades extrativas. Os segmentos sociais vulnerabilizados seu acesso ao território e aos recursos naturais como a água comprometidos ao mesmo tempo em que suas perspectivas de enunciação para denúncia das violências sofridas são restringidas. Já os fatores organizacionais e operacionais do setor minerário trazem à tona à opçáo pela tecnológica pela disposição de rejeitos minerários em grandes barragens, bem como às modalidades de resposta corporativa às oscilaçóes do mercado de commodities minerais. No caso específico da Samarco, os impactos da recessão após 2011 foram administrados com a elevação da produtividade. Mesmo em um cenário regressivo, a Samarco apostou no Projeto Quarta Pelotizaçáo (P4P), que possibilitou a expansão de $37 \%$ da capacidade instalada da empresa e a reduçáo dos custos operacionais, com repercussóes sobre as medidas de planejamento e prevenção estrutural de riscos. (Milanez et al, 2015).

Já sabemos que as fronteiras extrativas podem ser pensadas como locais onde são forjados "novos padróes de acesso, novas relações 
de controle e domínio do território e novas formas de governança” (Bury \& Norris, 2013: 94), mas a experiência do desastre nos revela que as fronteiras extrativas são também contextos morais em que são engendrados novos "modos de subjetivação" (Zhouri et al, 2017). Proponho, entáo, partimos da noção de subjetivação política, definida por Didier Fassin (2008:533) como “o advento de sujeitos e subjetividades na cena política" através de expedientes ou instrumentos "que permitem que os indivíduos sejam descritos (pelos outros) e identificados (por si mesmos) na arena pública” o que inclui toda uma constelação de categorias, discursos e representações que, nesse caso, pretendem identificar, circunscrever e classificar o público-alvo das medidas de reparação e compensação. Proliferam formas particulares de identificação, interpelação e gestáo desses sujeitos: impactado, afetado, atingido, vítima... Tais categorias mobilizam, por sua vez, circuitos sociais específicos com seus respectivos códigos e equipamentos: técnico, jurídico, terapêutico, político-pedagógico. No contexto desse desastre, são particularmente importantes duas categorias que informam a resposta institucional, mas sobretudo, corporativa ao desastre: são as noções de "evento" e "impactado" ambas centrais ao chamado PLCI - Programa de Levantamento e Cadastramento dos Impactados - (Synergia, 2016) elaborado pela consultoria Synergia, empresa prestadora de serviços contratada pelas mineradoras responsáveis pelo desastre.

Sublinho tais categorias náo apenas porque elas propóem um horizonte limitado de compreensão e atuaçáo corporativas, mas porque elas pretendem produzir simultaneamente a visibilidade, a espacialidade e a temporalidade dos danos, culminando no que o referido programa chama de "critérios de elegibilidade" dos atingidos. Critérios esses admitidos (mas não revelados) como condiçóes para o reconhecimento (e, consequentemente para seu oposto, a desqualificação) das reivindicaçóes daqueles que as apresentarem sob o registro dos "impactos" e sob o pleito da "reparação ou compensação". O eixo que ordena essa leitura corporativa é a idéia de que um evento intervenciona de forma involuntária sobre bens e processos econômicos. O instrumento "cadastro" dedica-se, então, 
à aferição de dados majoritariamente patrimoniais e censitários. A visibilidade em pauta está calcada na materialidade dos danos, entendida como consequências objetivas sobre propriedades e rendas. A demarcação de sua espacialidade acompanha a mesma lógica, restrita ao perímetro da lama ou ao alcance da pluma de rejeitos no mar e explícita na discriminação das chamadas "área afetada", "área residual" e "área remanescente". Já a temporalidade de referência é a própria situação do rompimento, designada evento (Zhouri et al, 2017).

No entanto, o que se passou e continua a se passar é bastante mais complexo do que essa leitura supóe. Os atingidos de Bento Rodrigues e Paracatu de Baixo ingressam nesses circuitos que lhes exigem, frequentemente, a objetivação de seu sofrimento, mediante linguagens, registros e tempos que lhes são alheios (Zhouri et al, 2017). Como parte desse processo, os regimes da burocracia e da organização política intervém em pelo menos em três domínios da experiência: (1) rotina: nova gestáo de seu tempo, agora referenciado pelas sequências de reunióes, assembleias e audiências; (2) narrativas: necessidade de adotar novas modalidades discursivas e vocabulários; (3) relaçóes intersubjetivas e controle expressivo sobre a apresentaçáo de si: o que compreende a construçáo de novas identidades, processos de estigmatização e os ajustamentos tornados necessários a partir da experiência de relocação compulsória.

Em contraste à narrativa linear de evento-impacto-medidas mitigadoras e reparadoras, nos contextos locais, os efeitos se derramam, se prolongam e se acumulam. É preciso destacar que o desastre instaura a experiência de um espaço e de uma temporalidade alheios, dirigidos e organizados por outrem a partir da desterritorializaçáo. Após quase três anos do rompimento de Fundáo, as famílias desterritorializadas pela lama permanecem residindo na sede urbana de Mariana, em casas alugadas pelas empresas minerárias responsáveis pelo desastre. Em estado de angústia, frustação e aflição, aguardam a construção dos distritos destruídos e o reassentamento das comunidades. As rupturas desencadeadas pelo desastre atingem, assim, o solo antes tácito das condições mínimas de previsibilidade, 
controle e autonomia. Não por acaso, abundam entre os atingidos metáforas que recolocam a empresa como a figura máxima daquele que seduz e trai, a Besta-Fera (Velho, 1987; Taussig, 2010). Otávio Velho (1987), já examinou tais representaçóes da besta-fera como o mau que vem de fora e atua por meio da seduçáo, cativando suas vítimas. Náo fortuitamente, no contexto do desastre, a empresa antes símbolo de redenção para o município em função dos postos de trabalho ofertados, após o rompimento, passa a ser chamada jocosamente chamada pelos afetados de Satanásmarco. Igualmente, nas celebraçóes da Semana Santa foi representada/personificada na figura de Judas, em um boneco que foi submetido ao ritual da "malhação do Judas". O ataque ao Judas portando o uniforme da empresa indica a mobilização do registro religioso e seu repertório de sentidos próprio para denunciar a ruptura da barragem também como uma ruptura da confiança.

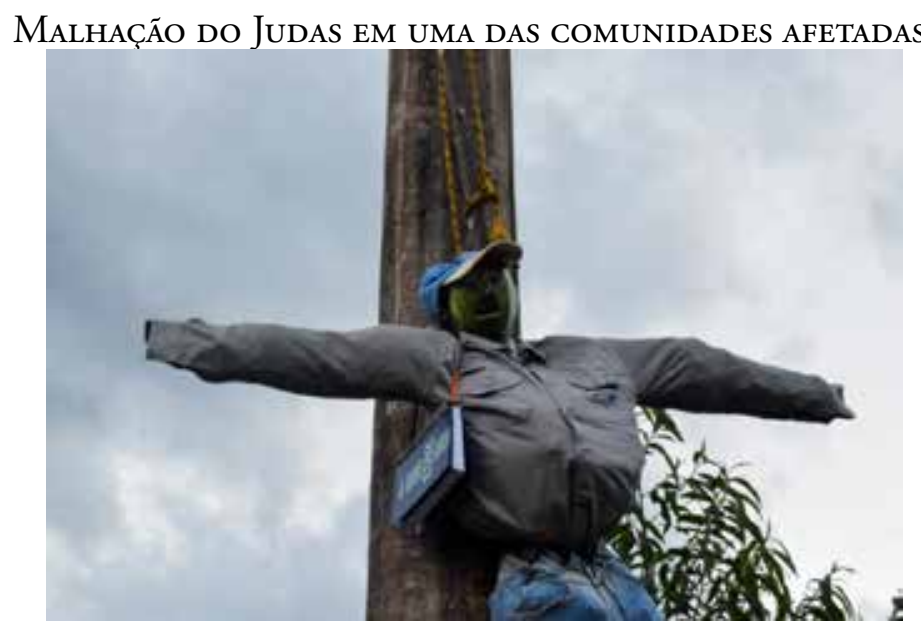

Foto: Jornal A Sirene, abril de 2017

Trata-se, portanto, de rupturas diversas. Em especial, há a ruptura na confiança acerca da continuidade da rotina, na estabilidade das estruturas da barragem, na segurança das comunidades e na eficiência corporativa no gerenciamento dos riscos. De súbito, as 
promessas da "utopia minerária" (Antonelli, 2009) revelaram-se deficientes, incluindo a inexistência de um plano de emergência efetivo que contemplasse a instalação e funcionamento de um simples dispositivo sonoro, essencial para o alerta e salvamento das vítimas fatais. Nas paredes em ruínas de Bento Rodrigues poucos dias após o rompimento, além dos rastros da lama, outras marcas podiam ser encontradas nas paredes como os sinais da equipe da Defesa Civil efetuados durante as operaçóes de salvamento e socorro às vítimas, mas sobretudo, outras interferências visuais sob a forma de mensagens anônimas inscritas nas paredes remanescentes. Em uma delas deixada sobre parte do muro da escola foi grafado: "Vivi grandes momentos da minha vida aqui" e "Samarco queria nos matar, mas Jesus nos salvou”.

Mensagens grafadas nas paredes em Bento Rodrigues

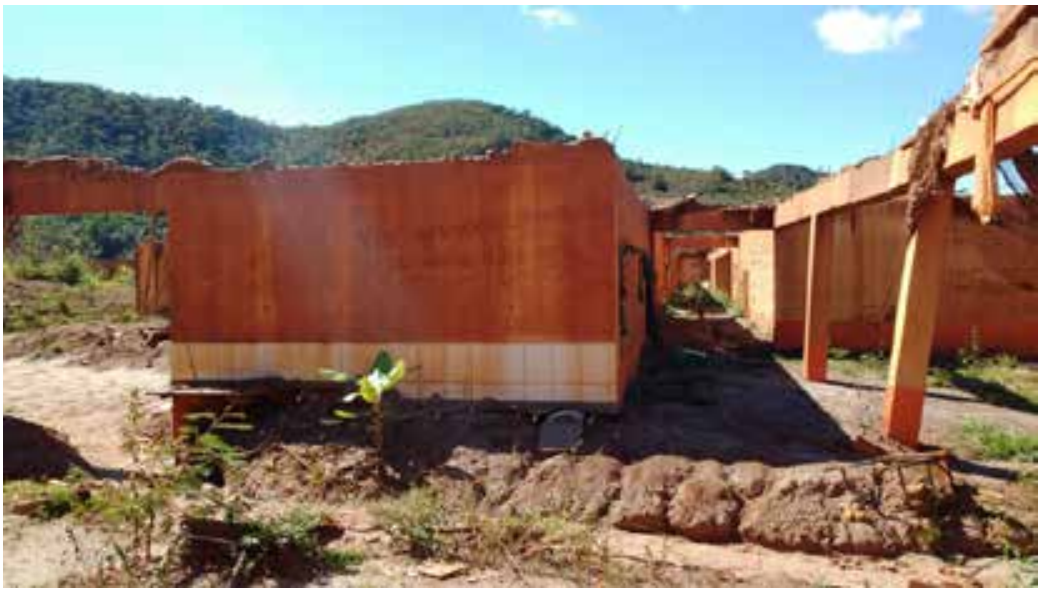

Foto: "Vivi grandes momentos da minha vida aqui"

Marcos Zucarelli, julho de 2016, Arquivo GESTA, 2016. 


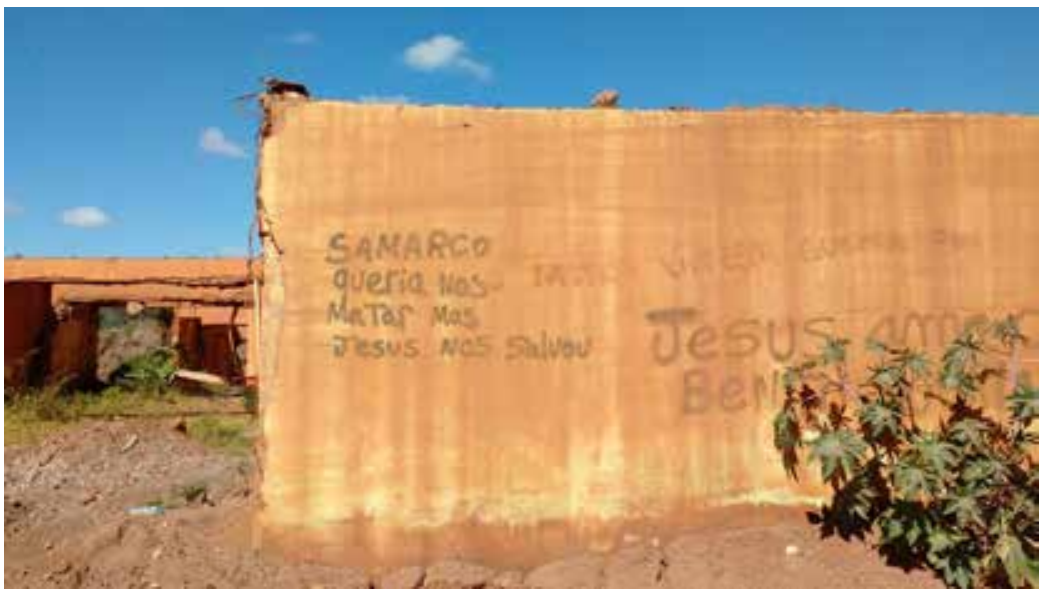

Foto: "Samarco queria nos matar, mas Jesus nos salvou" Marcos Zucarelli, junho de 2016. Arquivo GESTA, 2016.

Conforme revela o depoimento de J., morador de Bento Rodrigues, ao Jornal A Sirene, as marcas nas vidas, nas rotinas e nas relaçóes são mais duradouras do que sugere o enquadramento do desastre como "evento", termo utilizado para se referir ao rompimento da barragem de Fundão e às suas consequências no Plano de Cadastramento e Levantamento dos Impactados (PLCI).

A minha perda no Bento foi muito grande. Me tornei um cara fora de mim [...] de repente, amanheci sem nada. [...] Me tornei angustioso. Minha saúde acabou. Eu bambeei, sabe? Sou um cara, hoje, que passa o dia deitado, escutando meus CDs de música sertaneja [...] até na hora de dormir ligo o rádio para conseguir passar a noite. Escuto as músicas e as pessoas falando comigo a madrugada inteirinha. É isso que limpa meus pensamentos ruins. Pelejo, pelejo, mas eles não vão embora. Tenho um zumbido no 
ouvido do barulho da lama, que eu acho que tá na cabeça.

A experiência de bambear, de estar fora de si, guarda correlação com o processo descrito por M., moradora de Paracatu de Baixo e cujo depoimento reproduzimos no princípio do artigo. Embora sua casa não tenha sido arrastada pela onda de lama, M. foi também deslocada para a sede urbana do município, já que grande parte das estruturas, equipamentos e de sua vizinhança foram destruídos. $\mathrm{O}$ termo que ela mobiliza para interpretar e descrever sua vivência e de seus vizinhos e familiares como realocados na cidade de Mariana é "descontrole":

é complicado... então, é, sei lá, é muita coisa, sei que essa lama depois que veio, depois que ela chegou aqui ela descontrolou a vida de muitas pessoas. Mesmo que a Samarco paga o salário na conta [em referência ao auxilio financeiro pago aos atingidos pela empresa]. Mas descontrolou. Náo justifica náo, sabe? Náo justifica... porque todo mundo aqui podia até receber menos, mas tinha coisas que recompensava... você sabia que você estava cuidando do que era seu, hoje tá aqui [...] cuida lá de casa dos outros e enquanto cuida da casa dos outro é a minha que cai. Você já tá vendo a situação em que a minha está? Então, enquanto eu cuido da casa dos outros e a minha cai. E se no dia de amanhã a Samarco virar a cabeça, ai eu volto pra minha casa caindo? [grifos acrescidos]

Trata-se, portanto, entre outros efeitos, da privação dos recursos 
materiais e suportes propriamente sociais que amparam as rotinas, o senso de normalidade e as reivindicaçóes de identidade. Os processos permanecem, assim, no campo da subjetivação já que as categorias do meio técnico-corporativo ressoam sobre as relaçóes intersubjetivas locais com novas exigências não apenas para um "ajustamento forçado da palavra" (Valencio, 2014:35), mas para o controle expressivo sobre a apresentação de si, o que significa não apenas entender-se como portador do estigma e antecipar suas consequências, mas educar-se em um modo público de apresentação de sua condição. Trata-se conforme expõe Goffman (1981) de uma verdadeira "carreira moral". Ambas as narrativas assinalam a gravidade o deslocamento experimentado: físico e social, ampliado pelo processo de estigmatização dos 'realocados' por parte de comerciantes, moradores afluentes e dirigentes políticos da cidade de Mariana. Desse modo, tal como assinala Revet (2002), a experiência do deslocado é também aprendizagem do estigma.

O estigma se apresenta nesse caso, como um "fardo adicional" que se realiza na hostilidade, na política de "portas fechadas" e de discriminação (Bullard, 2006). O processo intervém, assim, não apenas sobre a dimensão psicológica, mas, sobretudo, social, que deteriora o mundo local desses sujeitos, em especial, seu acesso às redes que antes que lhes garantiam relacionamentos, bens e oportunidades (Kleinman \& Hall-Clifford, 2009). Um pequeno episódio que assisti na véspera do principal evento político organizado pelo Movimento dos Atingidos por Barragens para marcar um ano da tragédia pode ilustrar esse processo. $\mathrm{O}$ evento consistiu na realizaçáo de uma Marcha dos Atingidos que partiu de Regência (local afetado na foz do Rio Doce, no estado do Espírito Santo) e peregrinou até Mariana (em Minas Gerais), percorrendo o caminho em direção contrária àquela realizada pela lama. $\mathrm{O}$ evento fora designado ' $U m$ Ano de Lama e de Luta' e contou com a presença de autoridades do Ministério Público, artistas e apoiadores, muitos deles atingidos por outros empreendimentos, como as hidrelétricas recentemente construídas na regiáo norte do país. A marcha reuniu atingidos de várias regióes do país com o propósito de estabelecer intercâmbios e redes estratégicas. Na véspera da chegada da Marcha em Mariana, 
cartazes foram espalhados pela cidade, comunicando a realização do evento e convidando a população a participar. Os cartazes afixados na rua em que eu estava hospedada foram arrancados por um funcionário da pousada que no saláo do estabelecimento rasgava e jogava no lixo os cartazes enquanto bradava: "O cara que pregou isso aqui é de Rondônia. Agora você vê, de Rondônia? Ou é muito rico, ou é vagabundo".

A associação entre uma condição de ócio e o recebimento do chamado "cartão-benefício" da Samarco é apropriada pelos críticos com o intuito da construção de uma identidade depreciativa atribuída às vítimas transformadas em alvo de rumores e desacreditação social. $\mathrm{Na}$ sede urbana, circulam adjetivos depreciativos como "pé-delama”, "aproveitadores" e "vagabundos". Frequentemente as vítimas são recriminadas por seus esforços de mobilização, os quais são tomados como entraves à retomada das operaçóes da mineradora. Nessa atmosfera de tensão e hostilidade, os comerciantes exibem faixas em seus estabelecimentos anunciando seu apoio à empresa e outros moradores realizam protestos e manifestaçôes reivindicando o restabelecimento das atividades minerárias conduzidas pela Samarco. Organizados em um movimento que se intitula "Justiça Sim, Desemprego Não: Fica Samarco", os apoiadores investem na crítica pública incessante desferida aos atingidos.

Faixa de Apoio à Samarco na Cidade de Mariana

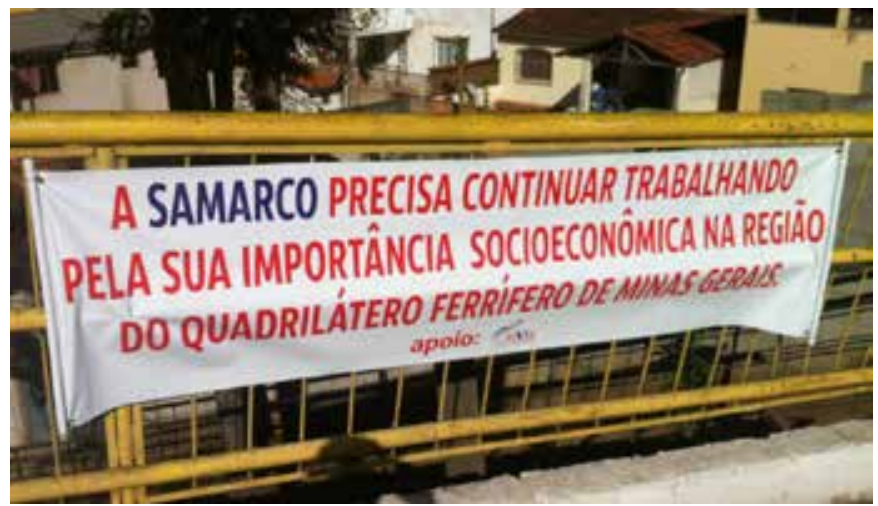

Foto: Max Vasconcelos. Arquivo GESTA, 2016. 
Nesse contexto, a insegurança sobre o modo como os atingidos seráo tratados em público conduz a uma gestão da informação social (Goffman, 1981). Constrangidos muitos moradores realocados em Mariana lançam máo das "práticas protetivas de encobrimento"(idem), evitando revelar publicamente sua identidade e origem, como ilustra minha conversa com dois moradores de Paracatu de Baixo: D. e N.

D. se encontra 'realocada' em Mariana, mas N. se recusou a deixar a localidade, em função dos cuidados com a lavoura e seus animais. Apartado de sua família que se dirigiu também para Mariana, ele permaneceu em Paracatu, procurando zelar por sua propriedade a despeito de estar cercado pelos rejeitos:

$\mathrm{N}$ : Eu vou te falar um negócio, homem tem que ser homem... eu vendo na internet $o$ que aquele homem fez ao pessoal daqui... Eu entrego na hora: "Aqui ó, sua chave tá aqui, eu moro na roça, mas não dependo de escutar isso." Ele chamou a turma daqui de sem vergonha. Você precisava ver. Ele pôs a turma daqui valendo nada.

D: É, eles xingam [insultam] mesmo. Muita gente não fala. Eu mesmo faço questão de falar que nem que sou daqui, porque eles xingam [insultam] o povo do Bento, de Paracatu, xingam [insultam] mesmo. Teve uma vez que teve uma reunião com o promotor no fórum. Ai juntou um monte de gente... Teve um monte de gente de Bento, Paracatu. Ai eles [moradores de Mariana] passavam na rua e gritavam: "Cambada de vagabundo, vai caçar trabalho, tá caçando dinheiro, vai caçar serviço". No meio da rua assim ...

- Você já passou alguma coisa assim lá em Mariana? 
D: Não, comigo mesmo não. Igual eu tô falando com você. Faço questão se perguntar de onde que eu sou, eu falo que sou de Mariana. Daqui não, porque eles xingam [insultam] demais.

N: Eu falo que eu sou do Paracatu, nascido e criado e nunca dependi da Samarco, toda vida fui trabalhador.

Conforme acentua o depoimento de $\mathrm{N}$. as noçóes de "aproveitadores" ou "vagabundos" atingem a ordem moral do grupo, em especial seu próprio sentido de dignidade e honra que fundamenta, segundo a ética camponesa dessas comunidades rurais, uma concepção de si coerente com os valores centrais que articulam: terra, trabalho e familia (Woortmann, 1990).

Em resposta à estigmatização, outros moradores produzem verdadeiros deslocamentos semânticos e transformam sua origem e identidade em plataforma de luta e reivindicações. Em uma de revelação voluntária, os atingidos ostentam signos identificadores, estrategicamente jogando com a visibilidade e a intrusibilidade dessa simbologia. No evento 'Uma Ano de Lama, Um Ano de Luta', os 'realocados' portavam como marcas identificadoras uma camiseta negra (simbolizando o luto) especialmente preparada para a ocasiáo e que trazia os seguintes dizeres: "Tomamos banho, mas a lama não sai". No verso, outras inscriçóes: desrespeito, preconceito, discriminação, descaso, intolerância, desumanidade - 05/11/2015: rompimento da barragem do Fundão - 05/11/2016: um ano depois nossa luta continua - Comunidade de Bento Rodrigues". A 'lama que não sai' interpela entáo a noção administrativa de impacto a qual permite abordar tais processos "em termos de soluções técnicas manejáveis" (Li, 2007:2). Abordados enquanto impactos cuja materialidade, temporalidade e espacialidade se encontram definidas e imediatamente apreensíveis, torna-se possível "circunscrever uma arena de intervenção sobre a qual os cálculos podem ser aplicados" (Li, 2002:2). Em termos pragmáticos, o discurso corporativo da reparação produz a 
legibilidade necessária: são conjuntos de bens a serem recompostos e/ou substituídos, estruturas a serem reconstruídas, circuitos econômicos a serem reativados, déficits a serem supridos e problemas a serem retificados. No entanto, conforme argumento, tomado sobre a perspectiva da vulnerabilização em contextos de expansão das fronteiras extrativas, o que o curso do desastre nos revela são conjuntos encadeados do que Gudynas (2016) chamou de efeitos-derrame, extraheciones e formas diversas de uma violência que constitui uma condição de possibilidade do próprio extrativismo.

\section{Camisetas preparadas pelos moradores de Bento Rodrigues}

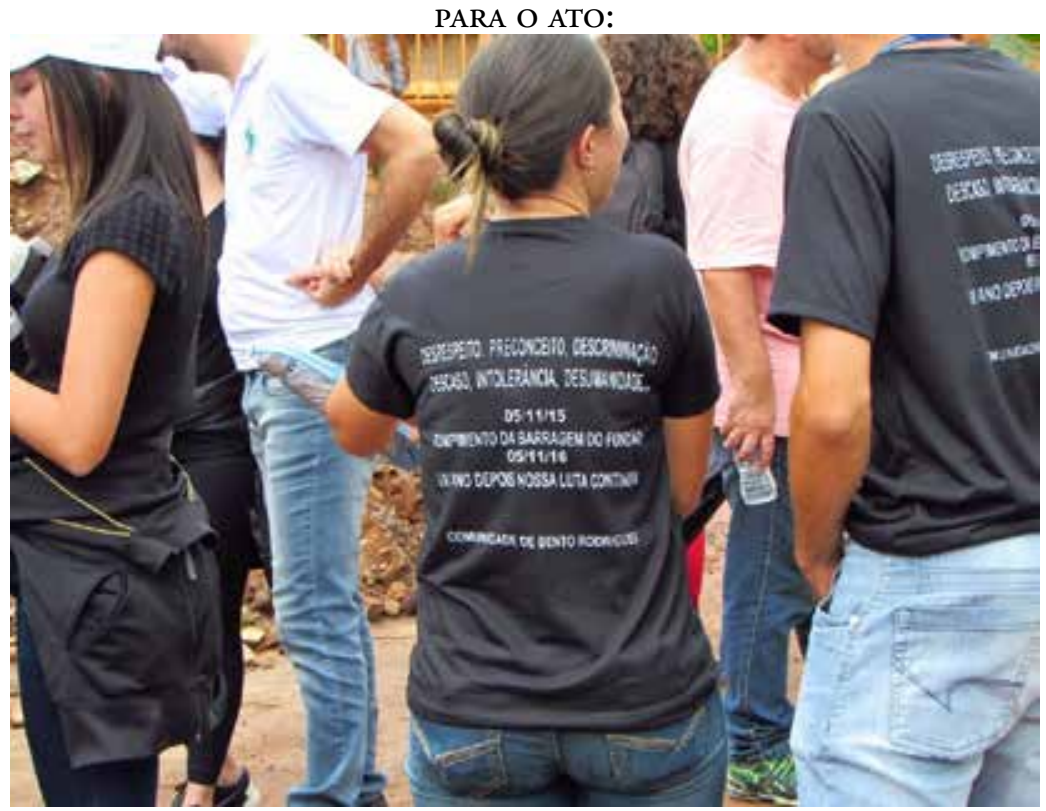

Foto: Marcos Zucarelli, novembro de 2016

Arquivo GESTA, 2016.

Assumindo as marcas do desastre como insolúveis e como elementos de uma identificação com vistas à denúncia, os atingidos reorganizam suas formas de ação política. Esse é o caso do grupo que se autodenomina 'Loucos por Bento' e que realiza regulares intervençóes 
como açóes de busca e resgate coletivo de objetos e materiais importantes na trajetória da comunidade, a exemplo dos bancos da praça, encontrados, identificados e resgatados pelos próprios moradores. O reparo dos acessos ao território da comunidade e a organização de festividades e celebraçóes religiosas em seu território original são ainda algumas das intervenções simbólicas e políticas promovidas pelo grupo.

Contudo, segundo nos lembra Goffman (1981), ao realizar esforços para retirar o estigma de sua condição diferencial, o estigmatizado se depara com um processo que "politiza toda a sua vida", transformando a condição de atingido em uma espécie de identificação que tende a totalizar sua experiência e identidade. A denúncia, assim, afirma e ressignifica, mas em contrapartida também o mantém em contínua exibição, em uma exposição que o torna acessível ao olhar estrangeiro curioso que se realiza, sobretudo, pelo assédio da cobertura midiática do desastre. $\mathrm{O}$ depoimento de L., atingida de Paracatu de Baixo, durante o mesmo evento revela algo desse processo:

Aqui [Mariana] não se tem liberdade, não se dorme bem. A gente não pode nem usar a praga do cartão, porque isso náo é um beneficio, gente, é uma praga, eles olham e dizem 'olha lá os aproveitadores'. As pessoas de lá [Paracatu] tinham berço, os outros pediam benção e licença para entrar em nossas casas... Agora se alguém morre vira noticia, se alguém fica triste vira notícia...

Os posicionamentos de autoridades públicas, em especial, de vereadores, deputados e prefeitos em apoio à retomada das operaçóes da empresa tendem a agravar o cenário de hostilidade e recriminação da luta dos atingidos. Conforme observado em outros casos de desastre no Brasil, tais segmentos podem contribuir no processo de hostilização às vítimas na medida em que "insuflam intolerâncias no meio civil, indispondo grupos sociais afluentes e camadas médias 
contra os que já sofrem continuados abusos frente a seus direitos” (Valencio, 2009:8). Como exemplo, destacamos o pronunciamento do deputado estadual Gustavo Corrêa, em audiência da Comissão Extraordinária de Barragens na Assembléia Legislativa de Minas Gerais. O referido deputado acentua:

Eu quero falar da importância da Samarco para a economia de nosso estado. A empresa sempre atuou de modo responsável. É preciso que a gente atue também de forma tranquila e sem emoção [...] Se a Samarco não voltar em breve, 18 milhóes de pessoas serão penalizadas. A tragédia física é $o$ rompimento da barragem, mas e quanto à tragédia social que vai significar $o$ fechamento da empresa? [...] Não podemos prejudicar milhares de cidadãos por conta de vaidades pessoais.

A remissão à "utopia minerária" que associa o projeto da Samarco ao crescimento econômico, ao aumento das receitas e das rendas locais é a base que permite a construção de compromissos e alinhamentos políticos que contribuem para contínua vulnerabilizaçáo dos atingidos. Nas fronteiras extrativas e seus desastres articulam-se, assim, em um mesmo horizonte, os interesses transnacionais relativos à geração de dividendos aos acionistas e as expectativas locais de modernidade, consumo e progresso (Ferguson, 1999) que fomentam a recriminação das vítimas como entraves ao desenvolvimento.

Para concluir essa reflexão sobre as marcas de um desastre em curso, recorro a outra tela de P. Trata-se de um quadro por ele produzido e intitulado "A Tristeza do Jeca". 


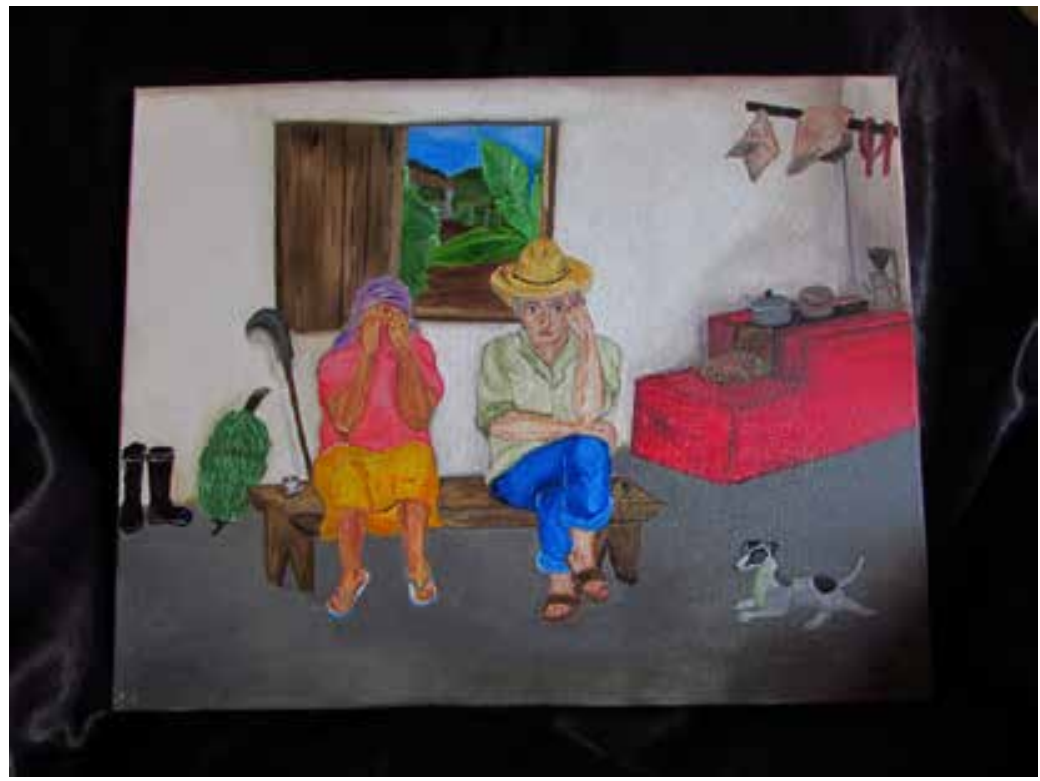

$\mathrm{Na}$ literatura brasileira, o personagem ficcional Jeca Tatu foi criado por Monteiro Lobato para representar a figura do trabalhador rural brasileiro, ou 'caipira'. O personagem foi caracterizado pelo romancista como uma figura do atraso, da ignorância pela ausência da formação escolar e da preguiça. Dialogando com tais estigmas, a imagem criada por P. retoma o tema do Jeca, mas o interpela na denúncia de um estado de aflição e tristeza. Na imagem criada P., a figura materna representada encobre seu rosto e, em particular, seus olhos com as máos. Ela chora e seu corpo expressa a angústia cuja causa ela náo quer ver. M. levou seis meses para conseguir ver, para retornar a Paracatu e se defrontar com a lama e suas marcas. Hoje, M. reivindica que certas marcas não sejam removidas, apagadas ou encobertas. Elas devem ser preservadas, sustentadas e exibidas como testemunhos da dor. Assegurar as marcas é impedir a fixaçáo do desastre como 'evento' do passado, é contestar as diferentes estratégias institucionais que buscam domesticar a apreensão dos danos. As inscriçóes são, portanto, narrativas visuais da experiência que permanece enquanto desgaste, deslocamento e descontrole, enfim, 
$o$ desastre em seu curso. Em contraste à assepsia dos cálculos e ao olhar distanciado dos cadastros, as marcas operam, relocando o efetivo o campo das experiências e dos danos sensíveis. Danos estes, conforme ressalta Antonelli (2009:75), "capazes de interrogar a verossimilhança e plausibilidade dessa utopia minerária”. Elas vão se tornando, assim, presenças imperativas do que não poderá ser silenciado ou denegado, são balizas para narrar o passado, entender o presente e costurar um futuro, mesmo que ainda incerto.

BiBLIOGRAFÍA:

ANTONELLI, Mirta A. (2009). "Minería Transncional y Dispositivos de Intervención en la cultura: la gestión del paradigma hegemónico de la minería responsable y desarollo sustentable".

SVAMPA, Maristella \& ANTONELLI, Mirta A. Minería transnacional, narrativas del desarollo y resistências sociales. Buenos Aires: Biblos.

BOURDIEU, Pierre (2012). "Efeitos de Lugar". BOURDIEU, Pierre. (Org.) A Miséria do Mundo. Petrópolis: Vozes.

BULLARD, Robert (2006). "Varridos pelo Furacão Katrina: reconstruindo uma 'nova' Nova Orleans usando o quadro teórico da justiça ambiental”. PACHECO, Tânia. \& HERCUlANO, Selene. Racismo Ambiental. Rio de Janeiro: Projeto Brasil Democrático e Sustentável. FASE.

BURY, Jeffrey. \& NORRIS, Timothy (2013). "Rocks, Rangers and Resistance: mining and conservation frontiers in the Cordillera Huayhuash, Peru". BEBBINGTON, Anthony. \& BURY, Jeffrey. Subterranean Struggles: new dynamics of mining, oil and gas in Latin America. Austin: University of Texas Press.

FASSIN, Didier (2008). "The Humanitarian Politcs of Testimony: subjectification through trauma in Israeli-Palestinian conflict". Cultural Anthropology, vol. 23(3).

FERGUSON, James. (1999) “The Copperbelt in Theory: from "emerging Africa" to the ethnography of decline". Expectations of Modernity: myths and meaning of urban life on the Zambian 
Copperbelt. Los Angeles: University of California Press.

GESTA/UFMG (2016). Parecer sobre o Cadastro Integrado do Programa de Levantamento e Cadastro dos Impactados (PLCI) elaborado pelas empresas Samarco e Synergia Consultoria Ambiental. Belo Horizonte. Disponível em: <http:// conflitosambientaismg.lcc.ufmg.br/noticias/parecer-sobre-ocadastro-integrado-do-programa-de-levantamento-e-cadastrodos-impactados-plci-elaborado-pelas-empresas-samarco-esynergia-consultoria-ambiental/>. Acesso em 02 mar. 2017.

GOFFMAN, Erwing. (1981) Estigma: notas sobre a manipulação da identidade deteriorada. Rio de Janeiro: Jorge Zahar Editor.

GUDYNAS, Eduardo (2015). Extractivismos: ecología, economia y politica de un modo de entender el desarollo y la naturaleza. Cochabamba: CEDIB.

GUDYNAS, Eduardo (2016). "Extractivismos en America del Sur: conceptos y sus efectos derrame". ZHOURI, Andréa; BOLADOS, Paola \& CASTRO, Edna. Mineração na América do Sul: neoextrativismo e lutas territoriais. São Paulo: Annablume. GUIVANT, Julia (1998). "A Trajetória das Análises de Risco: da periferia ao centro da teoria social". BIB, Rio de Janeiro, n. 46. HOGENBOOM, Barbara (2012). "Depoliticized and Repoliticized Minerals in Latin America. Journal of Developing Societies, $28(2)$.

IBASE (2013). Mapa das Minas. Instituto Brasileiro de Análises

Econômicas e Sociais, Disponível em: http://ibase.br/pt/ noticias/mapa-das-minas/. Acesso em 31/05/2017.

KLEINMAN, Arthur. \& HALL-CLIFFORD, Rachel (2009). "Stigma: a social, cultural and moral process". Journal of Epidemiology and Community Health. Vol. 63 (6).

LI, Tania Murray (2007). The Will to Improve: governmentatility, development and the practice of politics. London: Duke University Press.

MILANEZ, Bruno \& SANTOS, Rodrigo (2013). "Neoextrativismo no Brasil? uma análise da proposta do novo marco legal da mineração". Revista Pós Ciências Sociais, vol. 10, n. 19.

MILANEZ, Bruno.; SANTOS, Rodrigo.; WANDERLEY, Luiz.; 
MANSUR, Maíra; PINTO, Raquel Giffoni.; GONÇALVES, Ricardo.; COELHO, Tádzio P (2015). Antes Fosse Mais Leve a Carga: avaliação dos aspectos econômicos, politicos e sociais do desastre da Samarco/Vale/BHP em Mariana (MG). Relatório Final. PoEMAS, Grupo Política, Economia, Mineração, Ambiente e Sociedade. UFJF.

OLIVER-SMITH, Anthony (2002). “Theorizing Disasters: nature, power and culture". HOFFMAN, Sussana. \& OLIVERSMITH, Anthony. Catastrophe and Culture: the anthropology of disaster. Santa Fe: School of American Research Press.

PORTO, Marcelo Firpo Sousa (2000). "Consideraçóes sobre a dinâmica de regulação dos riscos industriais e a vulnerabilidade da sociedade brasileira”. HERCULANO, Selene.; PORTO, Marcelo Firpo Sousa. \& FREITAS, Carlos Machado. (Orgs.) Qualidade de Vida e Riscos Ambientais. Niterói: EdUFF.

REVET, Sandrine (2002). "Catégorisations, stigmatisation et reconstruction: comment les sinistrés vénézuéliens négocientils leurs appartenances". Réunion ERSIPAL (CREDAL), 2002. Disponível em: https://sciences-po.academia.edu/ SandrineRevet

SILVA, Telma Carvalho (2004). "Desastre como Processo: saberes, vulneralbildiade e sofrimento social no caso de Goiânia". LEINBING, Annette (Org.) Tecnologias do Corpo: uma antropologia das medicinas no Brasil. Rio de Janeiro: NAU Editora.

SYNERGIA. Programa de Levantamento e de Cadastramento dos Impactados, 2016.

TAUSSIG, Michael (2010) O Diabo e o Fetichismo da Mercadoria na América do Sul. São Paulo: Editora Unesp.

THOMAS, Allan Lavell (1993). "Ciencias Sociales y Desastres Naturales en America Latina: um encuentro inconcluso". MASKREY, Andrew. Los Desastres No Son Naurales. LA REDITG, Colombia: Tecer Mundo Editores.

VALENCIO, Norma Felicidade (2009). Da Morte da Quimera à Procura de Pégasu: a importância da interpretaçáo sociológica na análise do fenômeno denominado desastre.. Sociologia dos 
Desastres: construção, interfaces e perspectivas no Brasil. São Carlos: RiMA Editora.

VALENCIO, Norma Felicidade (2014). "Desastre como Prática Sociopolítica de Solapamento da Segurança Humana”. DO CARMO, Roberto \& VALENCIO, Norma. Segurança Humana no Contexto dos Desastres. São Carlos: Editora RiMA. VELHO, Otávio (1987). O Cativeiro da Besta-Fera. Religião \& Sociedade, 14/1.

ZHOURI, Andréa (2017). "Introduction: Anthropology and Knowledgeproduction in a 'minefield'”. Vibrant(Florianópolis), v. 14, n. 2. Disponível em: http:/www.vibrant.org.br/issues/ lastest-issue-v-14-n-2-05-082017/

ZHOURI, Andréa; VALENCIO, Norma Felicidade; OLIVEIRA, Raquel Santos Teixeira; ZUCARELLI, Marcos Cristiano; LASCHEFSKI, Klemens; SANTOS, Ana Flávia Moreira. (2016). "O desastre da Samarco e a política das afetaçóes: classificações e açóes que produzem o sofrimento social". Ciência e Cultura, 68(3).

ZHOURI, Andréa; OLIVEIRA, Raquel; ZUCARELLI, Marcos. C.; MAGALHAES, Max V. (2017). “The Rio Doce Mining Disaster in Brazil: between policies of reparation and the politics of affectations". Vibrant (Florianópolis), v. 14, n. 2. Disponível em: http://www.vibrant.org.br/issues/lastest-issuev-14-n-2-05-082017/

WOORTMANN, Klaas (1990). "Com Parente Não se Neguceia: o campesinato como ordem moral”. Anuário Antropológico, no 87.

Notas de PÁGina:

${ }^{1}$ Este trabalho é fruto de pesquisas coletivas realizadas no âmbito do Grupo de Estudos em Temáticas Ambientais (GESTA-UFMG), em especial, resulta dos seguintes projetos: "O Desastre e a Politica das Afetaçóes: compreensão e mobilização em um contexto de crise” sob coordenação da Profa. Andréa Zhouri e financiado pela Fundação de Amparo à Pesquisa do estado de Minas Gerais (FAPEMIG) e 
"Mineração: desastre sociotécnico e a gestão da crise" que conta com o auxílio do Conselho Nacional de Desenvolvimento Científico e Tecnológico (CNPq - Auxílio 404990/2016-9). Agradeço às referidas agências de fomento pelo apoio e à equipe do GESTA pelas anos de trabalho em partilha.

${ }^{2}$ Estrutura que integra o Complexo Minerário Alegria de propriedade da companhia SAMARCO cujas atividades estão ligadas à extração, transporte e beneficiamento de minério de ferro. A SAMARCO é controlada pelas empresas Vale e BHP Billiton. O complexo é composto por quatro lavras localizadas nos municípios de Mariana e Ouro Preto: Alegria Centro, Alegria Sul, Alegria Norte e Germano. Além de três concentradores, quatro usinas de pelotização, três minerodutos de $396 \mathrm{Km}$ de extensão, um terminal portuário e um sistema de barragens (Germano, Fundáo e Santarém) para disposição de rejeitos (IBASE, 2013).

${ }^{3}$ Reportagem: Comunidade celebra a Semana Santa em Bento Rodrigues. Jornal A Sirene. Disponível em: https://jornalasirene. wordpress.com/2017/04/17/comunidade-celebra-semana-santaem-bento-rodrigues/

${ }^{4} \mathrm{O}$ Jornal $A$ Sirene é organizado pelos próprios atingidos, professores e estudantes do curso de jornalismo da UFOP, Arquidiocese de Mariana e uma rede de colaboradores. Disponível em: https://jornalasirene.wordpress.com/2017/05/25/historias-danossa-gente/. Acesso em: 25/05/2017.

${ }^{5}$ Estado na regiáo Norte do Brasil, bastante distante de Minas Gerais, onde foram instaladas nos últimos anos as grandes hidrelétricas de Jirau e Santo Antônio. Alguns atingidos por essas represas participaram do evento "Um ano de lama, um ano de luta" em apoio aos afetados pelo desastre da Samarco.

Fecha de Recepción del Artículo: 20 de febrero de 2018 Fecha de Aceptación: 30 de mayo de 2018 